\title{
Soft Tissue Necrosis Upper Limb, CTCAE
}

National Cancer Institute

\section{Source}

National Cancer Institute. Soft Tissue Necrosis Upper Limb, CT CAE. NCI Thesaurus.

Code C143851.

A disorder characterized by a necrotic process occurring in the soft tissues of the upper extremity. 